\title{
Mitochondrial genome of Babesia orientalis, apicomplexan parasite of water buffalo (Bubalus babalis, Linnaeus, 1758) endemic in China
}

\author{
Lan He${ }^{1}$, Ying Zhang ${ }^{1}$, Qing-Li Zhang ${ }^{1}$, Wen-Jie Zhang ${ }^{1}$, Hui-Hui Feng ${ }^{1}$, Muhammad Kasib Khan ${ }^{1}$, Min Hu ${ }^{1}, 2$, \\ Yan-Qin Zhou ${ }^{1,2}$ and Jun-Long Zhao ${ }^{1,2^{*}}$
}

\begin{abstract}
Background: Apicomplexan parasites of the genus Babesia, Theileria and Plasmodium are very closely related organisms. Interestingly, their mitochondrial (mt) genomes are highly divergent. Among Babesia, Babesia orientalis is a new species recently identified and specifically epidemic to the southern part of China, causing severe disease to water buffalo. However, no information on the $\mathrm{mt}$ genome of $B$. orientalis was available.

Methods: Four pairs of primers were designed based on the full genome sequence of $B$. orientalis (unpublished data) and by aligning reported $\mathrm{mt}$ genomes of B. bovis, B. bigemina, and T. parva. The entire mt genome was amplified by four sets of PCR. The obtained $\mathrm{mt}$ genome was annotated by aligning with published apicomplexan $\mathrm{mt}$ genomes and Artemis software v11. Phylogenetic analysis was performed by using cox 1 and cob amino acid sequences.

Results: The complete mt genome of B. orientalis (Wuhan strain) was sequenced and characterized. The entire mt genome is 5996 bp in length with a linear form, containing three protein-coding genes including cytochrome $c$ oxidase I (cox1), cytochrome b (cob) and cytochrome c oxidase III (cox3) and six rRNA large subunit gene fragments. The gene arrangement in B. orientalis $\mathrm{mt}$ genome is similar to those of B. bovis, B. gibsoni and Theileria parva, but different from those of $T$. orientalis, T. equi and Plasmodium falciparum. Comparative analysis indicated that cox 1 and cob genes were more conserved than cox3. Phylogenetic analysis based on amino acid sequences of cox 1 , cob and cox $1+\operatorname{cob}$, respectively, revealed that $B$. orientalis fell into Babesia clade with the closest relationship to B. bovis.
\end{abstract}

Conclusions: The availability of the entire mt genome sequences of $B$. orientalis provides valuable information for future phylogenetic, population genetics and molecular epidemiological studies of apicomplexan parasites.

Keywords: Babesia orientalis, Mitochondrion, Mitochondrial genome, Phylogeny

\section{Background}

Mitochondria are essential organelles within cells and are responsible for energy transduction, metabolism, cell growth and survival [1-3]. Inside mitochondria, there is a genome called mitochondrial $(\mathrm{mt})$ genome. Mt genomes are present in almost all eukaryotic cells and have remarkable variations in size, structure, and organization [4-6].

\footnotetext{
* Correspondence: zhaojunlong@mail.hzau.edu.cn
${ }^{1}$ State Key Laboratory of Agricultural Microbiology, College of Veterinary

* Correspondence: zhaojunlong@mail.hzau.edu.cn
'State Key Laboratory of Agricultural Microbiology, College of Veterinary Medicine, Huazhong Agricultural University, Wuhan, Hubei, 430070, China ${ }^{2}$ Key Laboratory of Animal Epidemical Disease and Infectious Zoonoses, Ministry of Agriculture, Huazhong Agricultural University, Wuhan, Hubei, 430070, China
}

(c) 2014 He et al.; licensee BioMed Central Ltd. This is an Open Access article distributed under the terms of the Creative Commons Attribution License (http://creativecommons.org/licenses/by/2.0), which permits unrestricted use, distribution, and reproduction in any medium, provided the original work is properly credited. The Creative Commons Public Domain Dedication waiver (http://creativecommons.org/publicdomain/zero/1.0/) applies to the data made available in this article, unless otherwise stated.

The largest $\mathrm{mt}$ genome has been found in muskmelons with an estimated size of $2400 \mathrm{~kb}$ [7-9]. The smallest $\mathrm{mt}$ genome of only $6 \mathrm{~kb}$ in length has been reported in an apicomplexan parasite (Plasmodium) [10,11].

The structure of $\mathrm{mt}$ genome contains two major types, the linear form and the circular form. The circular forms are usually present in animal $\mathrm{mt}$ genomes with the size ranging from $15 \mathrm{~kb}$ to $20 \mathrm{~kb}$, containing $12-13$ proteincoding genes, 22 transfer RNA (tRNA) genes and two ribosomal RNA (rRNA) genes, and gene arrangements in the genomes are extremely stable [12]. The linear forms have been documented in many apicomplexan parasites, 
including Plasmodium, Babesia, Theileria and Eimeria $[5,10,11,13]$. Compared with animal $\mathrm{mt}$ genomes, the $\mathrm{mt}$ genomes of apicomplexan parasites encode only three protein-coding genes (cytochrome $\mathrm{c}$ oxidase subunits I [coxl] and III [cox3], and cytochrome b $[c o b])$ and six fragments of large subunit rRNA genes [14]. The gene arrangements are also different among animal $\mathrm{mt}$ genomes and apicomplexan parasites $\mathrm{mt}$ genome.

Meanwhile, in apicomplexan parasites, mitochondrial protein-coding genes have been extensively used as genetic markers for phylogenetic analysis at different taxonomic levels, serving as an ideal model for gene rearrangement, and evolutionary studies $[13,15]$. Most of the phylogenies of apicomplexan parasites were constructed using cox 1 or $c o b$ alone, however, in some cases, a combination of $c o x 1$ and $c o b$ was employed to evaluate the phylogenetic relationships $[13,16]$. In addition, $\mathrm{mt}$ genome sequences are also very valuable for population genetic studies [17-19] as reported in Plasmodium vivax, Plasmodium knowlesi, Trypanosoma cruzi [20-22].

$B$. orientalis is a tick-borne, intra-erythrocytic protozoan parasite causing buffalo babesiosis characterized by fever, anemia, icterus, haemoglobinuria and high mortality [23,24]. This species was first reported in 1987 and then identified as a new species named Babesia orientalis in 1997 [25]. The new species was discovered initially based on the differences in morphology, transmission, pathogenicity and endemic areas, compared to Babesia bigemina and Babesia bovis [25], and later confirmed by the phylogenetic analysis based on 18S rRNA and heat shock protein 70 (HSP70) genes [26,27]. The disease caused by $B$. orientalis is one of the most important parasitic diseases of buffalo in central and south China, resulting in enormous economic losses [27,28]. In spite of its importance, very limited information was available about this parasite, especially at the molecular level, including $\mathrm{mt}$ genome sequences and structures.

In the present study, B. orientalis (Wuhan strain) $\mathrm{mt}$ genome was determined and annotated. The structure was characterized and compared with those of related species. In addition, the evolution of structural divergence in the apicomplexan mt genomes was discussed.

\section{Methods}

\section{Parasite cultivation}

Babesia orientalis (Wuhan strain) was cultivated according to the protocol of $\mathrm{He}$ et al. [29]. In brief, two, 1year-old water buffalo, free of $B$. orientalis infection as confirmed by microscopy and real-time PCR [29], were splenectomized 14 days prior to $B$. orientalis infection. Each buffalo was subcutaneously injected with $4 \mathrm{ml}$ of $B$. orientalis-infected blood (Wuhan strain, percentage parasitized erythrocytes, PPE 1\%). Blood samples were collected everyday to monitor the parasitemia until PPE reached $3 \%$.

All the experimental animals were housed, fed and given clean drinking water in accordance with the stipulated rules for the regulation of the administration of affairs concerning experimental animals of P.R. China.

\section{B. orientalis mitochondria DNA sequencing}

The blood from experimentally infected buffalo was collected in EDTA. Parasite genomic DNA was extracted from B. orientalis-infected blood using QIAamp DNA Blood Mini Kit (Qiagen, Hilden, Germany) according to the manufacturer's instructions. The terminal inverted repeat (TIR) regions in the beginning and end of $B$. orientalis $\mathrm{mt}$ genome, 1-181 bp and 5835-5996 bp, were obtained by using $B$. bovis $\mathrm{mt}$ genome sequence to blast the full genome sequence of $B$. orientalis (unpublished data). Four pairs of primers were designed based on these two mtDNA sequences (1-181 bp and 5835-5996 bp) of $B$. orientalis and by aligning reported $\mathrm{mt}$ genomes of $B$. bovis (EU075182 and AB499088), B. bigemina (AB499085), and T. parva (Z23263 and AB499089) (Table 1 and Figure 1). The entire mt genome was amplified by P1 and R4. In order to confirm the mt genome, four sets of PCR were processed using primers $\mathrm{P} 1$ and R1, P2 and R2, P3 and R3, P4 and R4, respectively (Figure 1). Amplified products were purified and then ligated into the pMD19-T vector (TaKaRa Biotechnology), and the recombinant clones were sequenced using the ABI PRISM 377 DNA sequencer by following the manufacturer's instructions. The vector primers M13 (-47) and M13 (-48), as well as PCR primers, were used for the sequencing of $\mathrm{mt}$ genome.

\section{Gene annotation and sequence analysis}

Nucleotide sequences of $B$. orientalis mt genome (GenBank accession no. KF218819) were aligned with published mt genome sequences of Plasmodium falciparum (M76611), B. bovis (AB499088), T. parva (AB499089), and T. annulata (NT167255) by MAFFT (version 7) $[30,31]$ with manual corrections. Protein-coding genes

Table 1 Primers used for cloning of Babesiaorientalis mt genome sequence

\begin{tabular}{clc}
\hline Primers & Sequences & Position \\
\hline P1 & 5'-TGTTAAAAAACTTTATA-3' & 1-17 \\
R1 & 5'-ACTCTATAGGTATTTGACGTAATT-3' & $1749-1726$ \\
P2 & 5'-GCATGCAATACCGAACAGGGCCA-3' & $1592-1617$ \\
R2 & 5'-GCATTGTCTAATGTAGTTGTTC-3' & $3246-3225$ \\
P3 & 5'-AACGACTTCTCTATTGTCTCCAC-3' & $3368-3390$ \\
R3 & 5'-CAAATGAGTTATTGGGGAGC-3' & $5198-5179$ \\
P4 & 5'-ATAAATTAATTATAACTGTAGCTCC-3' & $5159-5183$ \\
R4 & 5'-TGTTAAAAAACTTATATTTGTTGAAATTT-3' & $5967-5996$ \\
\hline
\end{tabular}




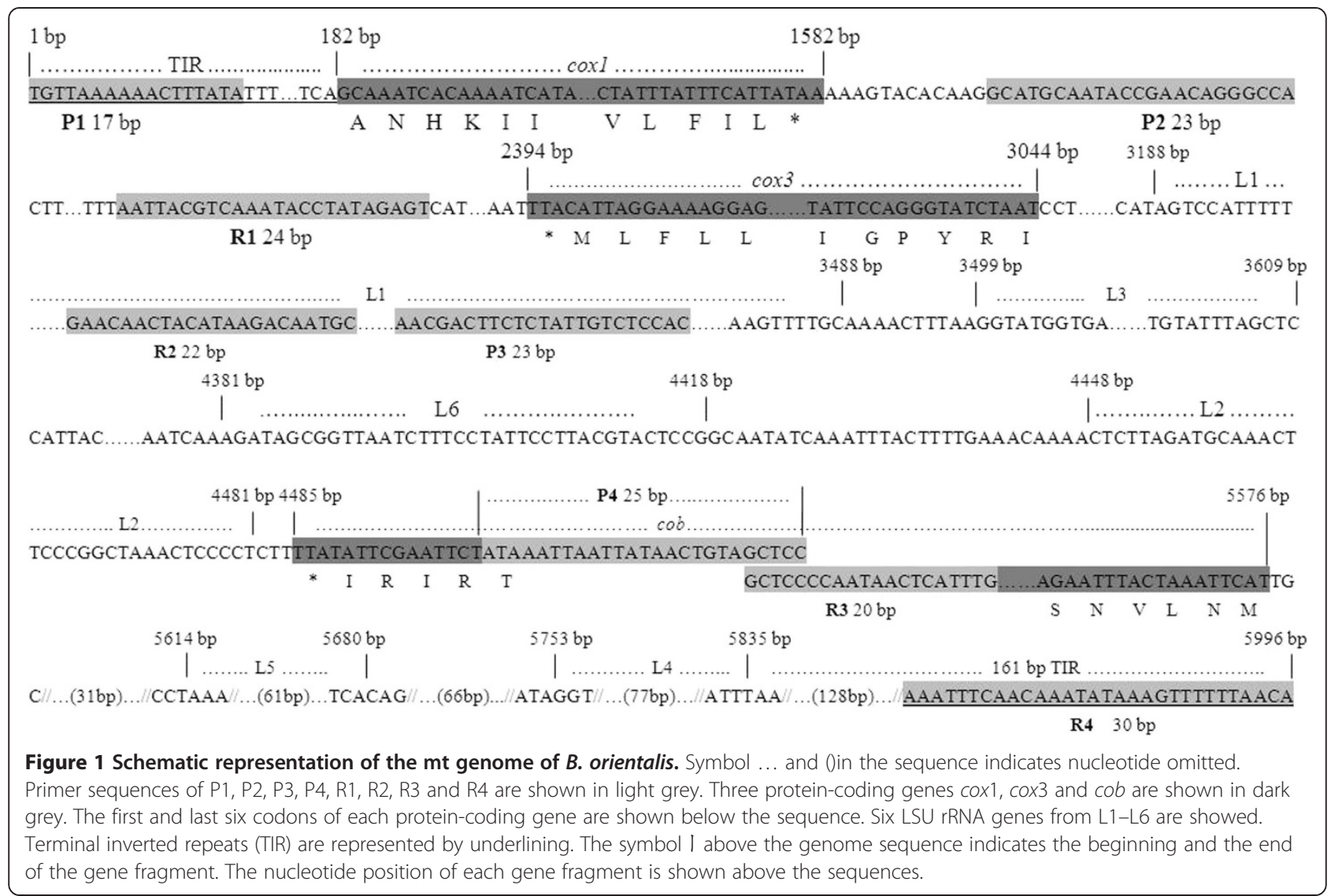

were predicted by comparing the previously annotated sequences from these four related species. To identify putative rRNA genes, mt DNA sequences or annotated rRNA gene fragments from the four related species were used as queries by pair-wise comparison (Blastn) in NCBI. The entire $B$. orientalis $\mathrm{mt}$ genome was subjected to tRNAscan SE 1.21 (http://lowelab.ucsc.edu/tRNAscan-SE/) using Mito/Chloroplast model option and Nematode Mito model for analyzing the existence of tRNA gene. Results from both models were compared, final annotation was determined according to B. bovis $\mathrm{mt}$ genome annotation. B. orientalis $\mathrm{mt}$ genome was also annotated using appropriate mitochondrial codes in Artemis software v11 [32,33].

Nucleotide sequence identities were calculated by pairwise comparison between 13 apicomplexan parasites including $B$. orientalis, another six Babesia species, five Theileria species and P. falciparum for each of the three protein-encoding genes. The data sets of $\operatorname{cox} 1$ (472 aa), cox3 (229 aa) or cob (358 aa) were aligned using MAFFT (version 7) employing the FFT-NS-i algorithm [31,34]. The alignment was manually edited using BioEdit 7.1.11 [35]. The nucleotide identities were determined through BioEdit 7.1.11.

\section{Phylogenetic analysis}

The concatenated amino acid sequences of $\operatorname{cox} 1, \operatorname{cox} 3$ and $c o b$ from 15 apicomplexan parasites (Table 2) were used for similarity analysis. For phylogenetic analysis, cox3 was not included, because cox3 has been presented

Table 2 Mitochondrial genome sequences of apicomplexa parasites used in the present study

\begin{tabular}{llll}
\hline Family & Species & $\begin{array}{l}\text { Size of } \mathbf{~ m t} \\
\text { DNA (bp) }\end{array}$ & $\begin{array}{l}\text { GenBank } \\
\text { accession no. }\end{array}$ \\
\hline Babesiidae & B. orientalis & 5996 & KF218819 \\
& B. bovis & 6005 & EU075182 \\
& B. bovis & 5970 & AB499088 \\
& B. bigemina & 5924 & AB499085 \\
B. caballi & 5847 & AB499086 \\
B. gibsoni & 5865 & AB499087 \\
Theileriidae & B. rodhaini & 6929 & AB624357 \\
T. parva & 5895 & Z23263 \\
T. parve & 5924 & AB499089 \\
T. equi & 8246 & AB499091 \\
T. orientalis & 5957 & AB499090 \\
T. annulata & 5905 & NT167255 \\
P. falciparum & 5967 & M76611 \\
\hline
\end{tabular}


in the nuclear genome rather than in mt DNA in some species, such as T. thermophila. A free-living ciliate, Tetrahymena thermophila [36], was used as the outgroup. The best-fit model of $c o x 1, c o b$, and $c o x 1-c o b$ combined nucleotide substitution was determined by JmodelTest 0.1.1 [37] selected by AIC calculations. A general time reversible model with a proportion of invariable sites and a gamma-shaped distribution of rates across sites $(\mathrm{TIM} 1+\mathrm{I}+\mathrm{G})$ substitution mode was used in PAUP* v4b10 [38] to explore neighbour-joining, parsimony and maximum likelihood methods. MrBayes v3.1.2 [39,40] was used to explore Bayesian phylogeny. Consensus trees were edited in MEGA v4.0.2 [41].

All water buffalo studies were carried out in compliance with the regulations (No. 5 proclaim of the Standing Committee of Hubei People's Congress) approved by the Standing Committee of Hubei People's Congress, P. R. China. The animal protocols were approved by Laboratory Animals Research Centre of Hubei province and the ethics committee of Huazhong Agricultural University (Permit number: 4200696657).

\section{Results and discussion}

\section{Characterization of $B$. orientalis $\mathrm{mt}$ genome}

The full length $\mathrm{mt}$ genome of $B$. orientalis was amplified by P1 and R4, and a 5996 bp fragment was obtained. In order to confirm the mt genome sequence, four overlapping fragments were amplified by using primer sets P1R1, P2-R2, P3-R3 and P4-R4 with expected sizes of 1749 bp, 1655 bp, 1831 bp and 838 bp, respectively. These four overlapping fragments covered the entire genome of $B$. orientalis (Figure 1). Each of the PCR products were then cloned into pMD19-T vector, and sequenced. A 5996 bp mt genome sequence of B. orientalis (Wuhan strain) was obtained by assembling all the sequenced fragments.

Sequence analysis indicated that $B$. orientalis $\mathrm{mt}$ genome was arranged in a linear form. It containing three protein-coding genes, cox 1 (cytochrome $c$ oxidase I), $c o b$ (cytochrome $b$ ), cox3 (cytochrome $c$ oxidase III) and six large subunit (LSU) rRNA gene fragments, but not any tRNA genes, which is consistent with those of other apicomplexan parasites studied to date (Figures 1 and 2) [11]. The mt genomes of apicomplexan parasites usually contain terminal inverted repeat (TIR) sequences with the size of around 440-450 bp [5]. However, in the $\mathrm{mt}$ genome of $B$. orientalis, $181 \mathrm{bp}$ and $161 \mathrm{bp}$ TIRs were identified from the beginning and the end, respectively (Figure 1). $\operatorname{cox} 1$, the first and fourth rRNA large subunit fragments (L1 and L4) are encoded by one strand of the mt genome, whereas cox3, cob, the second, the third, fifth and sixth fragments of large subunit rRNA genes (L2, L3, L5 and L6) are encoded by another strand

(a)

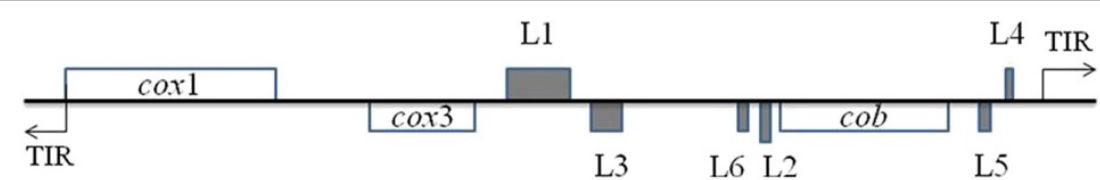

(b)

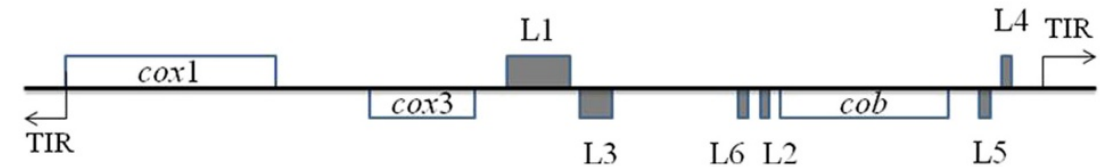

(c)

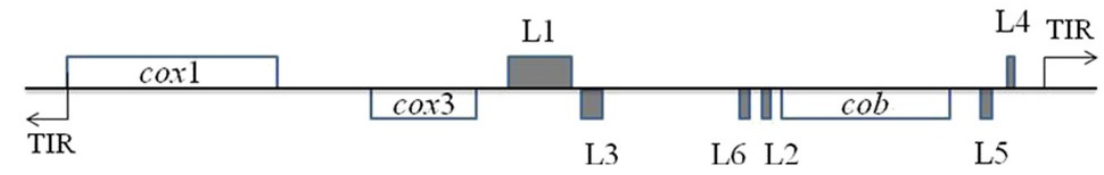

(d)

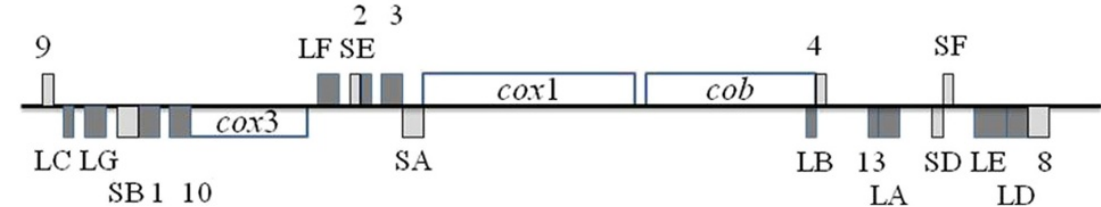

Figure 2 Schematic structure of mitochondrial genomes of Babesia orientalis (KF218819) (a) and three apicomplexan parasites including (b) B. bovis (AB499088), (c) Theileriaparva (Z23263) and (d) Plasmodium falciparum (M76611). Gene names above the bold line are transcribed from left to right, and those below are transcribed from right to left. White boxes indicate protein-coding genes, cox1 (cytochrome c oxidase I), cox3 (cytochrome c oxidase III), and cob (cytochrome b). Fragments of LSU (L1 - L6, LA - LG, 1, 2, 3, 10 and 13) and SSU (SA, SB, $\mathrm{SD}-\mathrm{SF}, 4,8$ and 9) rRNA genes are shown by dark and light gray boxes. TIR represents terminal inverted repeats. 
Table 3 Nucleotide sequence identity (percentage) between Babesiaorientalis and 12 apicomplexan parasites (a) Identity analyses based on the sequences of cox 1

\begin{tabular}{|c|c|c|c|c|c|c|c|c|c|c|c|c|}
\hline Species & 1 & 2 & 3 & 4 & 5 & 6 & 7 & 8 & 9 & 10 & 11 & 12 \\
\hline \multicolumn{13}{|l|}{ 1. B. orientalis (KF218819) } \\
\hline 2. B. bovis (EU075182) & 80.6 & & & & & & & & & & & \\
\hline 3. B. bovis (AB499088) & 80.6 & 99.8 & & & & & & & & & & \\
\hline 4. B. bigemina (AB499085) & 82.4 & 81.1 & 81.2 & & & & & & & & & \\
\hline 5. B. caballi (AB499086) & 82.2 & 80.9 & 81.1 & 85.0 & & & & & & & & \\
\hline 6. B. gibsoni (AB499087) & 81.6 & 79.0 & 79.2 & 81.6 & 82.9 & & & & & & & \\
\hline 7. B. rodhaini (AB624357) & 68.4 & 67.0 & 67.0 & 66.3 & 67.5 & 69.5 & & & & & & \\
\hline 8. T. parva (Z23263) & 73.9 & 71.2 & 71.1 & 72.7 & 72.8 & 74.3 & 66.5 & & & & & \\
\hline 9. T. parva (AB499089) & 74.8 & 72.1 & 72.0 & 73.6 & 73.7 & 75.2 & 67.4 & 98.6 & & & & \\
\hline 10. T. equi (AB499091) & 38.9 & 39.3 & 39.3 & 38.9 & 39.0 & 41.0 & 38.7 & 39.1 & 39.3 & & & \\
\hline 11. T. orientalis (AB499090) & 74.0 & 72.1 & 72.1 & 73.0 & 73.5 & 74.6 & 66.9 & 78.1 & 79.1 & 38.0 & & \\
\hline 12. T. annulata (NT167255) & 71.7 & 68.9 & 68.9 & 70.6 & 70.7 & 71.3 & 63.3 & 84.0 & 83.8 & 37.2 & 74.3 & \\
\hline 13. P. falciparum (M76611) & 61.1 & 60.9 & 60.9 & 60.2 & 60.2 & 62.1 & 61.5 & 59.6 & 60.1 & 36.0 & 60.0 & 58.0 \\
\hline
\end{tabular}

(b) Identity analyses based on the sequences of cox3

\begin{tabular}{|c|c|c|c|c|c|c|c|c|c|c|c|c|}
\hline \multicolumn{13}{|l|}{ 1. B. orientalis (KF218819) } \\
\hline 2. B. bovis (EU075182) & 80.9 & & & & & & & & & & & \\
\hline 3. B. bovis (AB499088) & 74.2 & 92.5 & & & & & & & & & & \\
\hline 4. B. bigemina (AB499085) & 68.7 & 68.1 & 73.7 & & & & & & & & & \\
\hline 5. B. caballi (AB499086) & 65.6 & 67.2 & 72.4 & 77.6 & & & & & & & & \\
\hline 6. B. gibsoni (AB499087) & 64.7 & 63.3 & 67.6 & 71.4 & 72.7 & & & & & & & \\
\hline 7. B. rodhaini (AB624357) & 34.4 & 34.6 & 34.2 & 33.0 & 32.2 & 32.2 & & & & & & \\
\hline 8. T. parva (Z23263) & 53.1 & 52.3 & 47.5 & 47.5 & 49.3 & 49.4 & 28.3 & & & & & \\
\hline 9. T. parva (AB499089) & 54.1 & 53.7 & 56.8 & 56.8 & 59.0 & 59.1 & 31.6 & 83.5 & & & & \\
\hline 10. T. equi (AB499091) & 29.6 & 29.8 & 29.7 & 28.8 & 29.3 & 31.8 & 32.8 & 29.5 & 33.3 & & & \\
\hline 11. T. orientalis (AB499090) & 33.0 & 34.3 & 34.4 & 35.8 & 32.8 & 34.3 & 51.6 & 28.4 & 31.8 & 33.0 & & \\
\hline 12. T. annulata (NT167255) & 53.1 & 52.9 & 48.3 & 48.1 & 48.8 & 50.5 & 29.4 & 82.6 & 67.0 & 29.4 & 29.3 & \\
\hline 13. P. falciparum (M76611) & 45.8 & 44.4 & 42.3 & 43.5 & 43.2 & 46.6 & 31.7 & 40.6 & 43.2 & 32.5 & 32.5 & 41.3 \\
\hline
\end{tabular}

\section{(c) Identity analyses based on the sequences of $c o b$}

1. B. orientalis (KF218819)

2. B. bovis (EU075182)

3. B. bovis (AB499088)

4. B. bigemina (AB499085)

5. B. caballi (AB499086)

6. B. gibsoni (AB499087)

7. B. rodhaini (AB624357)

8. T. parva (Z23263)

9. T. parva (AB499089)

10. T. equi (AB499091)

11. T. orientalis (AB499090)

12. T. annulata (NT167255)

13. P. falciparum (M76611)
81.7

$81.7 \quad 99.9$

$81.0 \quad 80.3$

$82.0 \quad 80.6 \quad 80.7 \quad 84.6$

$\begin{array}{llll}78.1 & 77.1 & 77.0 & 78.2\end{array}$

$\begin{array}{llll}33.7 & 34.8 & 34.8 & 34.1\end{array}$

$\begin{array}{lllllll}58.5 & 59.0 & 58.9 & 58.9 & 58.7 & 60.1 & 30.9\end{array}$

$62.2 \quad 62.7 \quad 62.6$

$62.6 \quad 62.4$

63.9

32.7

94.0

$69.3 \quad 68.2$

68.1

$68.0 \quad 68.8$

67.7

$33.6 \quad 58.2$

$61.2 \quad 60.6$

60.5

$61.9 \quad 62.0$

$\begin{array}{lll}63.2 & 33.3 \quad 56.5\end{array}$

61.8

$62.7 \quad 62.2$

62.1

$62.6 \quad 62.5$

64.1

$32.9 \quad 68.8$

$60.1 \quad 61.3$

$33.9 \quad 33.9$

33.9

$33.9 \quad 34.0$

$34.7 \quad 56.0 \quad 32.9$

34.9

61.7

60.6

$33.5 \quad 33.5$ 

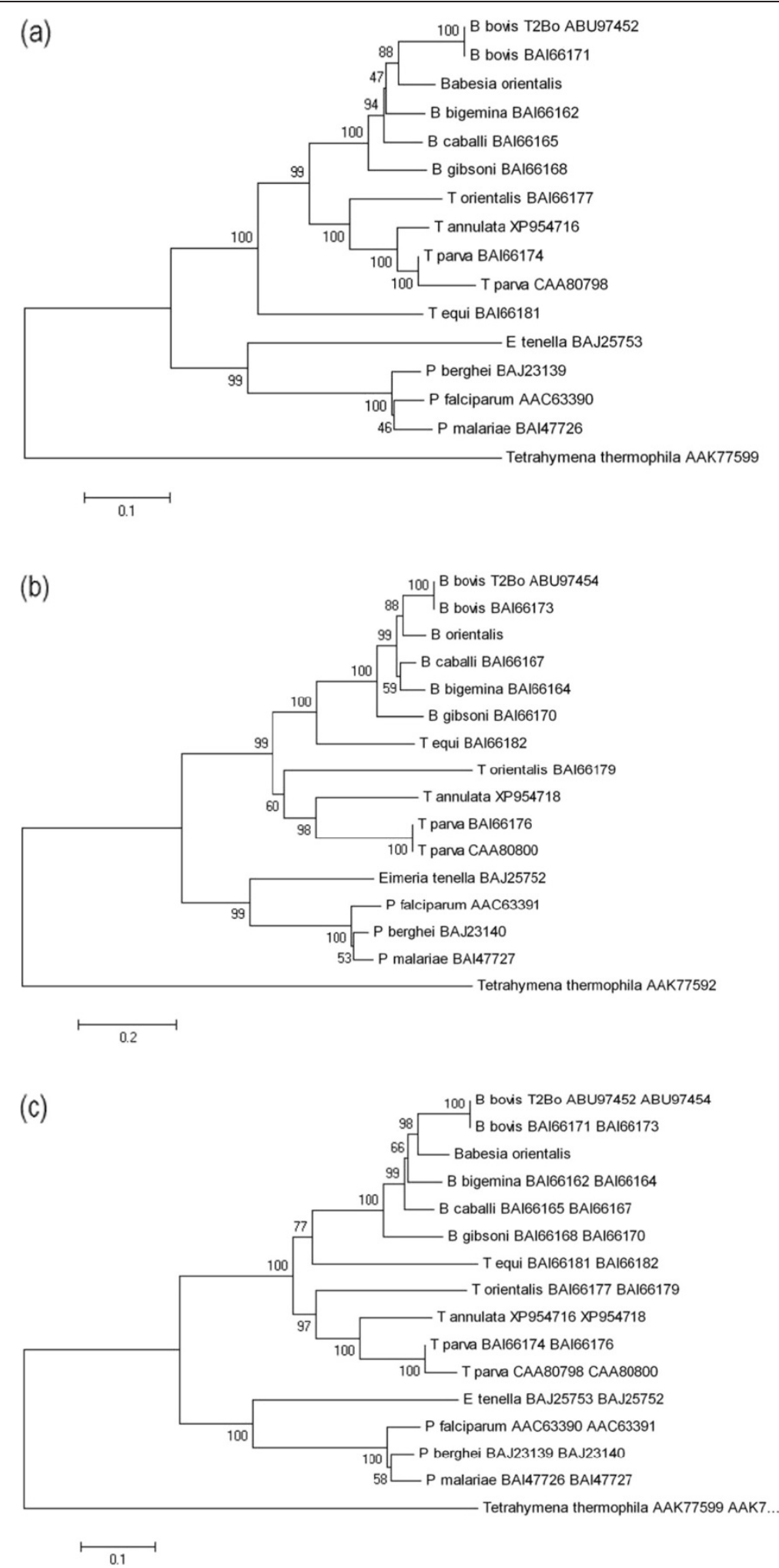

Figure 3 Phylogenetic analyses of $\operatorname{cox} 1$ (a), $\operatorname{cob}(\mathbf{b})$ and $\operatorname{cox} 1+\operatorname{cob}(\mathbf{c})$ amino acid sequences of $\boldsymbol{B}$. orientalis. Each neighbor-joining tree shows the phylogenetic relationship of protein coding genes of Babesiaorientalis $\mathrm{mt}$ genome determined in this study with other apicomplexan parasites. Bootstrap values at the nodes are indicating the degree of support for each cluster. Vertical lengths in each tree are not significant and are merely set for clarity. GenBank accession numbers are indicated on the right of each species name. Tetrahymena thermophila was used as an outgroup. 
(Figure 2a). The arrangement and predicted transcriptional direction of three protein-coding genes are the same as that of B. bovis (Figure 2b), B. gibsoni (not shown), and Theileria parva (Figure 2c), however, it greatly differed from that of $T$. orientalis, $T$. equi (not shown) and P. falciparum (Figure 2d) [5].

In this study, BLAST analysis of the entire mt genome sequence of $B$. orientalis to NCBI databases revealed that the $\mathrm{mt}$ genome sequence of $B$. orientalis was most similar to those of B. bovis (EU075182 and AB499088), with an identity of $87 \%$. The other related species were B. caballi, B. bigemina and B. gibsoni, showing their mt genome sequence identities of $86 \%, 85 \%$ and $84 \%$ with that of $B$. orientalis, respectively. However, nucleotide identities were greatly different for the sequences of three protein-coding genes cox $1, \operatorname{cox} 3$ and $c o b$, when compared among different species. Pairwise comparison has been carried out among 13 different apicomplexan species including $B$. orientialis, another six Babesia species, five Theileria species and $P$. falciparum (see Table 3). The nucleotide sequence differences among 13 species ranged from $38.7 \%$ to $99.8 \%$ for cox1 (Table 3a), from $28.8 \%$ to $92.5 \%$ for cox3 (Table $3 \mathrm{~b}$ ) and $32.7 \%$ to 99.9\% for cob (Table 3c), respectively. These results indicated that $\operatorname{cox} 1$ and $c o b$ genes were more conserved than cox3 gene. The different extent of conservation in the protein-coding genes suggested that $\mathrm{mt}$ genome sequences could be used as a gene marker for population evolutionary studies.

\section{Phylogenetic analysis}

The majority of phylogenetic studies in the phylum apicomplexa have utilized $18 \mathrm{~S}$ rRNA genes [27,42], which allow the analysis of the ancient relationships or strains and species differentiation by focusing on the highly conserved regions defining the critical secondary structure, or the more variable internal transcribed spacer regions, respectively. Because of different extent of conservation of three protein-coding genes and important function of $\mathrm{mt}$ genome, the extent of sequence difference might reflect the phylogenetic relationship across species of apicomplexan parasites. So the mitochondrion sequences may provide an alternative approach to conduct these studies $[5,10,13]$.

To analyze the phylogenetic relationship of $B$. orientalis with other apicomplexan parasites, phylogenetic trees were constructed with the amino acid sequences of $\operatorname{cox} 1$, $c o b$ and $c o x 1+c o b$ using neighbor-joining (NJ), maximum likelihood (ML), maximum parsimony (MP) and Bayesian phylogenetic methods. The trees obtained from three data sets by different methods were consistent with no significant changes in the topology or in the bootstrap values (Figures 3a,b, and c). The NJ trees constructed with $c o x 1, c o b$ and $c o x 1+c o b$ sequences have been presented as a representative (Figure 3). All three NJ trees displayed the same topology with high bootstrap values. $B$. orientalis appeared in the Babesia clade, and it's most close to $B$. bovis. However, the bootstrap value was higher in the tree constructed by $\operatorname{cox} 1+c o b$ as compared to those of cox 1 and cob. These results suggested that the combined amino acid sequences of $\operatorname{cox} 1$ and $c o b$ may be more reliable in studying evolutionary relationships than the sequences of single gene. The relationship of $B$. orientalis with other apicomplexan parasites revealed by all trees from $\mathrm{mt}$ genome sequences were consistent with that from the previous phylogenetic trees based on $18 \mathrm{~S}$ rRNA and heat shock protein 70 (HSP70) gene [26,27]. These results demonstrated that the mt genome sequences are useful for the phylogenetic studies of apicomplexan parasites.

\section{Conclusion}

In this study, we first reported the 5996 bp linear mitochondrion genome of $B$. orientalis. This mt genome contains 6 LSU rRNA gene fragments and three proteincoding genes, but no tRNA gene. Gene arrangement in the $\mathrm{mt}$ genome of $B$. orientalis is similar to those of $B$. bovis, B. gibsoni, and T. parva, but different from those of $T$. orientalis, $T$. equi and $P$. falciparum. Phylogenies based on the amino acid sequences of $\operatorname{cox} 1$ or $c o b$ alone and $\operatorname{cox} 1+\operatorname{cob}$ combined all indicated that $B$. orientalis is closest to $B$. bovis, which is in agreement with the previous phylogenetic studies of $B$. orientalis. The availability of the entire $\mathrm{mt}$ genome sequences of $B$. orientalis provides valuable information for future phylogenetics, population genetics and molecular epidemiological studies of apicomplexan parasites.

\section{Competing interests}

The authors declare that they have no competing interests.

\section{Authors' contributions}

All the authors contributed significantly to this study. LH and JLZ designed the experiments, carried out field and laboratory experiments, interpreted the results, and wrote the manuscript. YZ, QLZ, WJZ and HHF participated in cloning experiments and sequence analysis. MKK, MH and YQZ carried out editing and also helped in writing the manuscript. All the authors of the manuscript read and approved the final version of the manuscript.

\section{Acknowledgements}

The study was partially supported by Special Fund for Agro-scientific Research in the Public Interest (201003060-01-06), China Postdoctoral Science Foundation Grant (2012 M511629) and the National Natural Science Foundation of China (30671575).

Received: 4 September 2013 Accepted: 26 January 2014

Published: 28 February 2014

\section{References}

1. Frederick RL, Shaw JM: Moving mitochondria: establishing distribution of an essential organelle. Traffic 2007, 8(12):1668-1675.

2. Taylor-Brown $\mathrm{E}$, Hurd $\mathrm{H}$ : The first suicides: a legacy inherited by parasitic protozoans from prokaryote ancestors. Parasit Vectors 2013, 6(1):108.

3. Kaczanowski S, Sajid M, Reece SE: Evolution of apoptosis-like programmed cell death in unicellular protozoan parasites. Parasit Vectors 2011, 4:44. 
4. Gray G, Maxwell D, Villarimo A, Mclntosh L: Mitochondria nuclear signaling of alternative oxidase gene expression occurs through distinct pathways involving organic acids and reactive oxygen species. Plant Cell Rep 2004, 23(7):497-503.

5. Hikosaka K, Watanabe Y-I, Tsuji N, Kita K, Kishine H, Arisue N, Palacpac NMQ, Kawazu S-i, Sawai H, Horii T: Divergence of the mitochondrial genome structure in the apicomplexan parasites, Babesia and Theileria. Mol Biol Evol 2010, 27(5):1107-1116.

6. Feagin JE: Mitochondrial genome diversity in parasites. Int J Parasitol 2000, 30(4):371-390.

7. Lung B, Zemann A, Madej MJ, Schuelke M, Techritz S, Ruf S, Bock R, Hüttenhofer A: Identification of small non-coding RNAs from mitochondria and chloroplasts. Nucleic Acids Res 2006, 34(14):3842-3852.

8. Ward BL, Anderson RS, Bendich AJ: The mitochondrial genome is large and variable in a family of plants (Cucurbitaceae). Cell 1981, 25(3):793-803.

9. Palmer DN, Fearnley IM, Walker JE, Hall NA, Lake BD, Wolfe LS, Haltia M, Martinus RD, Jolly RD: Mitochondrial ATP synthase subunit c storage in the ceroid-lipofuscinoses (Batten disease). American J Medical Genet 1992, 42(4):561-567.

10. Hikosaka K, Tsuji N, Watanabe Y-I, Kishine H, Horii T, Igarashi I, Kita K, Tanabe K Novel type of linear mitochondrial genomes with dual flip-flop inversion system in apicomplexan parasites, Babesia microti and Babesia rodhaini. BMC Genomics 2012, 13(1):1-9.

11. Hikosaka K, Watanabe Y-I, Kobayashi F, Waki S, Kita K, Tanabe K: Highly conserved gene arrangement of the mitochondrial genomes of 23 Plasmodium species. Parasitol Int 2011, 60(2):175-180.

12. Boore JL: Animal mitochondrial genomes. Nucleic Acids Res 1999 27(8):1767-1780.

13. Lin R-Q, Qiu L-L, Liu G-H, Wu X-Y, Weng Y-B, Xie W-Q, Hou J, Pan H, Yuan Z-G, Zou F-C: Characterization of the complete mitochondrial genomes of five Eimeria species from domestic chickens. Gene 2011, 480(1):28-33.

14. Preiser P, Wilson R, Moore P, McCready S, Hajibagheri M, Blight K, Strath M, Williamson D: Recombination associated with replication of malarial mitochondrial DNA. The EMBO J 1996, 15(3):684.

15. Lei R, Shore GD, Brenneman RA, Engberg SE, Sitzmann BD, Bailey CA, Kimmel LM, Randriamampionona R, Ranaivoarisoa JF, Louis EE Jr: Complete sequence and gene organization of the mitochondrial genome for Hubbard's sportive lemur (Lepilemur hubbardorum). Gene 2010, 464(1):44-49.

16. Hikosaka K, Nakai Y, Watanabe Y-I, Tachibana S-I, Arisue N, Palacpac NMQ, Toyama T, Honma H, Horii T, Kita K: Concatenated mitochondrial DNA of the coccidian parasite Eimeria tenella. Mitochondrion 2011, 11(2):273-278.

17. Hajibabaei M, Singer GA, Hebert PD, Hickey DA: DNA barcoding: how it complements taxonomy, molecular phylogenetics and population genetics. Trends Genet 2007, 23(4):167-172.

18. Fernando P, Pfrender ME, Encalada SE, Lande R: Mitochondrial DNA variation, phylogeography and population structure of the Asian elephant. Heredity 2000, 84(3):362-372.

19. Birungi J, Munstermann LE: Genetic structure of Aedes albopictus (Diptera: Culicidae) populations based on mitochondrial ND5 sequences: evidence for an independent invasion into Brazil and United States. Ann Entomol Soc Am 2002, 95(1):125-132.

20. Lewis MD, Llewellyn MS, Yeo M, Acosta N, Gaunt MW, Miles MA: Recent independent and anthropogenic origins of Trypanosoma cruzi hybrids. PLoS Neglect Trop Dis 2011, 5(10):e1363.

21. Lee K-S, Divis PC, Zakaria SK, Matusop A, Julin RA, Conway DJ, Cox-Singh J, Singh B: Plasmodium knowlesi: reservoir hosts and tracking the emergence in humans and macaques. PLoS Pathog 2011, 7(4):e1002015.

22. Jongwutiwes S, Putaporntip C, Iwasaki T, Ferreira MU, Kanbara H, Hughes AL: Mitochondrial genome sequences support ancient population expansion in Plasmodium vivax. Mol Biol Evol 2005, 22(8):1733-1739.

23. Liu ZL, Ma LH, Zhang GD, Gao XS: An investigation of babesiosis in buffaloes in Hubei province. Acta Vet Zootechnica Sin 1986, 17(1):49-54 (in chinese).

24. Liu ZL, Ma LH, Gao XS, Cheng XJ: Study on babesiosis of buffaloes in Hubei Province II: experimental infection demonstrated Rhipicephalus haemaphysaloides haemaphysaloides to be the vector of babesiosis in buffaloes. Acta Vet Zootechnica Sin 1987, 18(3):173-178 (in chinese).

25. Liu Z, Zhao J, Ma L, Yao B: Babesia orientalis sp. nov. parasitized in buffalo bubalus bubalis in China (Piroplasmida: Babesiidae). Acta Vet Zootechnica $\sin 1997,28(1): 84-89$.
26. He L, Liu Q, Quan M, Zhou D-N, Zhou Y-Q, Zhao J-L: Molecular cloning and phylogenetic analysis of Babesia orientalis heat shock protein 70. Vet Parasitol 2009, 162(3):183-191.

27. Liu Q, Zhao J, Zhou Y, Liu E, Yao B, Fu Y: Study on some molecular characterization of Babesia orientalis. Vet Parasitol 2005, 130(3):191-198.

28. He L, Zhou Y-Q, Oosthuizen MC, Zhao J-L: Loop-mediated isothermal amplification (LAMP) detection of Babesia orientalis in water buffalo (Bubalus babalis, Linnaeus, 1758) in China. Vet Parasitol 2009, 165(1):36-40.

29. He L, Feng H-H, Zhang Q-L, Zhang W-J, Khan MK, Hu M, Zhou Y-Q, Zhao J-L: Development and evaluation of real-time PCR assay for the detection of Babesia orientalis in water buffalo (Bubalus bubalis, Linnaeus, 1758). J Parasitol 2011, 97(6):1166-1169.

30. Katoh K, Frith MC: Adding unaligned sequences into an existing alignment using MAFFT and LAST. Bioinformatics 2012, 28(23):3144-3146.

31. Katoh K, Standley DM: MAFFT multiple sequence alignment software version 7: improvements in performance and usability. Mol Biol Evol 2013, 30(4):772-780

32. Carver T, Harris SR, Berriman M, Parkhill J, McQuillan JA: Artemis: an integrated platform for visualization and analysis of high-throughput sequence-based experimental data. Bioinformatics 2012, 28(4):464-469.

33. Rutherford K, Parkhill J, Crook J, Horsnell T, Rice P, Rajandream M-A, Barrell B: Artemis: sequence visualization and annotation. Bioinformatics 2000, 16(10):944-945.

34. Katoh K, Misawa K, Kuma Kl, Miyata T: MAFFT: a novel method for rapid multiple sequence alignment based on fast Fourier transform. Nucleic Acids Res 2002, 30(14):3059-3066.

35. Hall TA: BioEdit: a user-friendly biological sequence alignment editor and analysis program for Windows 95/98/NT. Oxford University Press 1999, 41:95-98.

36. Brunk $C F$, Lee $L C$, Tran $A B$, Li J: Complete sequence of the mitochondrial genome of Tetrahymena thermophila and comparative methods for identifying highly divergent genes. Nucleic Acids Res 2003, 31(6):1673-1682.

37. Posada D: jModelTest: phylogenetic model averaging. Mol Biol Evol 2008 , 25(7):1253-1256.

38. Swofford D: PAUP 4.0 b10: phylogenetic analysis using parsimony. Sunderland, MA, USA: Sinauer Associates; 2002.

39. Huelsenbeck JP, Ronquist F: MRBAYES: Bayesian inference of phylogenetic trees. Bioinformatics 2001, 17(8):754-755.

40. Ronquist F, Huelsenbeck JP: MrBayes 3: Bayesian phylogenetic inference under mixed models. Bioinformatics 2003, 19(12):1572-1574.

41. Tamura K, Dudley J, Nei M, Kumar S: MEGA4: molecular evolutionary genetics analysis (MEGA) software version 4.0. Mol Biol Evol 2007, 24(8):1596-1599.

42. Allsopp M, Cavalier-Smith T, DeWaal D, Allsopp B: Phylogeny and evolution of the piroplasms. Parasitology 1994, 108:147-147.

doi:10.1186/1756-3305-7-82

Cite this article as: He et al:: Mitochondrial genome of Babesia orientalis, apicomplexan parasite of water buffalo (Bubalus babalis, Linnaeus, 1758) endemic in China. Parasites \& Vectors 2014 7:82

\section{Submit your next manuscript to BioMed Central and take full advantage of:}

- Convenient online submission

- Thorough peer review

- No space constraints or color figure charges

- Immediate publication on acceptance

- Inclusion in PubMed, CAS, Scopus and Google Scholar

- Research which is freely available for redistribution 